\title{
Genetic variations in dry matter production and physiological nitrogen use efficiency in rice (Oryza sativa $L$.) varieties
}

\author{
Sachiko Namai, Kazunobu Toriyama and Yoshimichi Fukuta* \\ Japan International Research Center for Agricultural Sciences (JIRCAS), 1-1 Ohwashi, Tsukuba, Ibaraki 305-8686, Japan
}

\begin{abstract}
The objective of this study was to investigate varietal differences in dry matter production and physiological nitrogen use efficiency (PNUE) using a wide range of rice (Oryza sative L.) varieties at an early growth stage. The results provide useful information for breeding suitable varieties for cultivation under conditions of low soil fertility or with reduced fertilizer use for sustainable agriculture. Thirty-one rice varieties were used, and seedlings were grown under 8 nitrogen treatment conditions. The effects of natural variations in embryo and/or endosperm size on initial growth were controlled for by comparing the relative dry weight (RDW) of nitrogen-treated samples and controls. The rice varieties were classified into 5 groups by cluster analysis. Overall, the present study found that there are wide variations in PNUE among varieties with similar levels of RDW under varying nitrogen conditions. Variations in PNUE were greater under lower nitrogen conditions; in contrast, variations in RDW were greater under higher nitrogen conditions. These data, along with those of other studies, indicate differences in nitrogen use efficiency between Indica- and Japonicatypes, upland and lowland varieties, and landraces and improved types.
\end{abstract}

Key Words: genetic variation, relative dry weight, physiological nitrogen use efficiency, vegetative growth stage, rice (Oryza sativa L.).

\section{Introduction}

Since the 1960s, rice (Oryza sativa L.) yield has increased markedly through the so-called Green Revolution, with yield improvements achieved mainly through the use of high-yield varieties and the heavy application of chemical fertilizer (Bohlool et al. 1992, Fischer 1998, Khush 1999). The production of chemical fertilizers requires large amounts of fossil fuel, and their heavy use may lead to eutrophication of lakes, rivers, and ground water. These activities have resulted in serious environmental problems (Boys 2005). It is important to achieve efficient use of nitrogen in chemical fertilizers, not only through cultivation techniques, but also by breeding varieties with high nitrogen use efficiency (NUE) and reducing nitrogen inputs from farming to the environment (Lafitte 1998, Ladha et al. 1998, Singh et al. 1998, Raun and Johnson 1999, Hasegawa 2003, Good et al. 2004, Fageria et al. 2008).

Investigating the response of rice to different concentrations of nitrogen will aid in the development of high NUE varieties, and the selection of suitable genotypes for each cultivated condition. Many studies have investigated varietal differences in yield and NUE. Ju et al. (2006) and Samonte et al. (2006) have pointed out that demonstrating varietal differences in yield and NUE was complex because rice

Communicated by T. Kato

Received January 5, 2009. Accepted July 16, 2009.

*Corresponding author (e-mail: zen@jircas.affrc.go.jp) yield was influenced by inherent factors such as the number of productive culms, grains per panicle, and 1000-grain weight, in addition to plant management conditions. However, measuring varietal differences in dry matter production and NUE at the vegetative growth stage eliminates those additional variables affecting yield.

Many studies have investigated varietal differences in nitrogen response at an early growth stage in rice cultured in solution. For example, Ichii and Tsumura (1989) studied varietal differences in the absorption rate of a fixed nitrogen concentration using 76 rice varieties, 51 Japonica-type (32 lowland varieties and 19 upland varieties) and 25 Indicatype. They observed that Indica-type varieties had a significantly higher absorption rate of ammonium nitrogen than Japonica-type varieties at the early vegetative growth stage. Ehara et al. (1990) investigated varietal differences in growth rate and related characteristics at the seedling stage using 35 rice varieties of different ecotypes and growth types grown in 7 nutrient concentrations of culture solution and concluded that nitrogen content per leaf area may be one of the main factors leading to varietal differences in dry matter increase, with neither ecotype nor growth type corresponding to this characteristic. Amin et al. (2002) studied varietal differences in nitrogen response during early growth using 8 Indica-type varieties and a culture solution with 0.1 $\mathrm{mM}$ nitrogen and reported that landrace varieties showed a higher relative growth rate than improved varieties under low nitrogen treatment conditions.

No previous studies of varietal differences in nitrogen 
response have accounted for the factors of agroecotype, geographic adaptation, and degree of improvement. Furthermore, although it is necessary to control for the effects of embryo and/or endosperm size on initial growth in order to investigate varietal differences at early growth stages (Ehara et al. 1990), most studies of varietal differences in nitrogen response have not considered these effects.

In the present study, we selected varieties based on 3 criteria: agroecotype (Indica- or Japonica-type), adaptation to lowland or upland, and degree of improvement (from landrace to modern variety). Furthermore, we used the relative dry weight (RDW, \%) of plants treated with nitrogen in comparison to nitrogen-free controls to control for differences in growth resulting from seed attributes.

The objective of this study was to investigate varietal differences in response to nitrogen using a wide range of rice varieties at an early growth stage in order to provide essential information for the breeding of varieties that are suitable for cultivation under a range of soil fertility conditions or with a small quantity of basal nitrogen dressing for environmentally friendly sustainable agriculture.

\section{Materials and Methods}

\section{Rice varieties}

A total of 31 varieties were used to evaluate the diversity of nitrogen use efficiency (NUE) in rice (Oryza sativa L.). The varieties were classified into 2 types, Indica and Japonica, both of which included varieties with varying ecosystems (irrigated lowland, rain-fed lowland and upland) and degrees of improvement, with improved varieties defined as those developed by crossbreeding after 1922 (Table 1).

Of 14 Indica-type varieties, 5 were landraces and 9 were improved types. The 5 native varieties, Dular, Kasalath, Surjamkuhi, Tadukan and Tetep, are cultivated in the tropical countries of India (first 2 varieties), Bangladesh, the Philippines and Vietnam, respectively. The 9 improved varieties were IR 8, IR 24, IR 36, IR 64, Hokuriku 143, Milyang 23, Taichung Native 1, Takanari and Mahsuri. All but Mahsuri are semi-dwarf. Taichung Native 1, the first semi-dwarf Indica-type variety developed through crossbreeding (Athwal 1971), was bred in Taiwan by crossing a Chinese semidwarf variety, Dee Geo Woo Gen, with Tsai Yuan Chung and released in 1956 (Chang 1961, Spielmeyer et al. 2002). The 4 varieties IR 8, IR 24, IR 36 and IR 64 were developed at the International Rice Research Institute (IRRI) by introducing the semi-dwarf gene, $s d-1$, from Dee Geo Woo Gen and were released from 1966 to 1985 . Milyang 23 was bred using the semi-dwarf variety IR 24, and was released in Korea in 1976. Takanari was bred in Japan by crossing Milyang 25 and Milyang 42, which were both developed by introducing $s d-1$ to IRRI-bred and Japonica varieties, and was released in 1990 (Imbe et al. 2004). Hokuriku 143 was developed in Japan as a non-shattering mutant line from a Chinese semi-dwarf variety, Nan-jing 11 (Fukuta et al. 1994). These semi-dwarf varieties were developed and released as a new ideotype in many countries in tropical and temperate irrigated regions from 1966 to 1990 (Khush 1999, Ashikari et al. 2002, Peng et al. 2008) and contributed to increased rice yields. Mahsuri is cultivated over wide areas in tropical countries. It was developed through backcross breeding between Taichung 65 and Mayang Ebos 80 as the recurrent parent in the Indica-Japonica hybridization program of the Food and Agriculture Organization (FAO) and was released in Malaysia in 1965 (Yamakawa et al. 1977).

The 17 Japonica-type varieties included 8 landraces and 9 improved varieties. Of the landraces, leading varieties in several tropical and temperate countries, 6 are cultivated in upland areas, Azucena and Davao in the Philippines, Kibi and Oiran in Japan, Trembese in Indonesia, and Moroberekan in Guinea. The other landrace varieties, Basmati 217 in India and Kamenoo in Japan, are cultivated in irrigated areas. All 9 improved varieties, Kotobukimochi, Owarihatamochi, Koshihikari, Reiho, Dontokoi, Aichiasahi, Nipponbare, Akihikari, and Toride 1, were bred in Japan. Kotobukimochi and Owarihatamochi are upland varieties released in 1948 and 1951, respectively. Koshihikari was cross-bred from Norin 22 and Norin 1, released in 1956, and remains a leading variety in Japan. Reiho and Dontokoi also include Norin 22 in their pedigree, and were released in 1966 and 1995, respectively. Aichiasahi and Nipponbare were bred at Aichi Agricultural Research Center and released in 1922 and 1963, respectively. Akihikari was cross-bred from Toyonishiki and Reimei at Aomori Agricultural Research Center as a high yielding variety, and was released in 1976. Toride 1 was developed to introduce high blast resistance from the Indian variety TKM1 into the Japanese variety Norin 8 (Nagai et al. 1970) and was released in 1970.

\section{Cultivation}

Seeds from each of the 31 varieties were sown in plastic trays (Minoru Industrial Co., Ltd., Seedling box "Naedoko", $27 \mathrm{~cm} \times 60 \mathrm{~cm})$ filled with sterilized soil that the Japan Agriculture (JA) in Ibaraki provided for raising seedling without fertilizer, to investigate dry matter production at an early vegetative growth stage. A total of 155 seeds ( 5 seeds per each variety, one tray include the set of 31 varieties) were sown in the plastic tray filled with 1.3 sterilized soil for the each nitrogen treatment. Before nitrogen treatment, the seedlings were raised in deionised water to exhaust endosperm nutrients. The plastic trays were put in containers filled with 22 litres of deionized water per tray and placed in a greenhouse at $25^{\circ} \mathrm{C}$, with more than 14 hours of natural light during the daytime.

A culture solution with a concentration 0.71 times that described by Mae and Ohira (1981) was applied 24 days after sowing along with various concentrations of nitrogen: 0,1 , $2,5,10,20,40$, and $80 \mathrm{mg} \mathrm{N} \mathrm{L}^{-1}$. Ammonium nitrate $\left(\mathrm{NH}_{4} \mathrm{NO}_{3}\right)$ was used as the nitrogen source. Concentrations of all other essential elements were uniform, and the $\mathrm{pH}$ of each solution was adjusted to approximately 5.5. The culture solution was replaced every day. Five seedlings of each 
Table 1. Varieties used in the nitrogen response experiments and their classifications

\begin{tabular}{|c|c|c|c|c|}
\hline \multirow{3}{*}{ Cluster group ${ }^{a}$} & \multicolumn{4}{|c|}{ Variety groups (Origin) ${ }^{b}$} \\
\hline & \multicolumn{2}{|c|}{ Indica-type } & \multicolumn{2}{|c|}{ Japonica-type } \\
\hline & Landrace & Improved & Landrace & Improved \\
\hline $\mathrm{I}$ & Kasalath (IN) & - & - & - \\
\hline II & Dular (IN) & - & Basmati 217 (IN) & - \\
\hline \multirow[t]{6}{*}{ III } & - & - & Azucena (PH) & Kotobukimochi (JP, 1948) \\
\hline & & & Davao $(\mathrm{PH})$ & Owarihatamochi (JP, 1951) \\
\hline & & & Kibi (JP) & Dontokoi (JP, 1995) \\
\hline & & & Moroberekan (GN) & \\
\hline & & & Oiran (JP) & \\
\hline & & & Trembese (ID) & \\
\hline \multirow[t]{3}{*}{ IV } & Surjamkuhi (BD) & Mahsuri (MA, 1965) & Kamenoo (JP) & Koshihikari (JP, 1948) \\
\hline & Tadukan (PH) & Hokuriku 143 (JP, 1987) & & Reiho (JP, 1966) \\
\hline & Tetep (VN) & Takanari (JP, 1990) & & \\
\hline \multirow[t]{6}{*}{$\mathrm{V}$} & - & Taichung Native 1 (TW, 1956) & - & Aichiasahi (JP, 1922) \\
\hline & & IR $8(\mathrm{PH}, 1966)$ & & Nipponbare (JP, 1963) \\
\hline & & IR $24(\mathrm{PH}, 1974)$ & & Toride $1(\mathrm{JP}, 1970)$ \\
\hline & & IR $36(\mathrm{PH}, 1976)$ & & Akihikari (JP, 1976) \\
\hline & & Milyang 23 (KR, 1976) & & \\
\hline & & IR $64(\mathrm{PH}, 1985)$ & & \\
\hline
\end{tabular}

\footnotetext{
${ }^{a}$ Classification of cultivars based on responses to nitrogen.

${ }^{b}$ Letters and dates in parentheses indicate country or region of origin and year of release. BD: Bangladesh, GN: Guinea, IN: India, ID: Indonesia, JP: Japan, KR: Korea Republic, MA: Malaysia, PH: Philippines, TW: Taiwan, VN: Vietnam.
}

variety were grown for 14 days after the beginning of nitrogen treatment, and dry matter weights and nitrogen concentrations were then measured.

Evaluation of nitrogen efficiency for dry matter production

All plants were collected 14 days after the initiation of nitrogen treatment and dried for $48 \mathrm{~h}$ at $80^{\circ} \mathrm{C}$. The dry matter weight of the leaves and stems was measured for each plant. Nitrogen content was measured using a total nitrogen analyzer (Sumigraph NC900; Sumika Chemical Analysis Service, Tokyo, Japan). The relative dry weight (RDW) of each variety treated with each nitrogen concentration was calculated using equation (1):

$$
\text { RDW }(\%)=\frac{D W \text { of } N \text { treatment }}{D W \text { of non }-N \text { control }} \times 100
$$

where DW is the dry matter weight of the leaves and stems (mg).

The physiological nitrogen use efficiency (PNUE; efficiency of dry matter production per $\mathrm{mg}$ of absorbed nitrogen) was calculated for each variety and each nitrogen treatment using equation (2):

$$
\text { PNUE }=\frac{D W \text { of } N \text { treatment }-D W \text { of non }-N \text { control }}{N C \text { of } N \text { treatment }-N C \text { of non }-N \text { control }}
$$

where DW is as above and $\mathrm{NC}$ is the nitrogen content of the leaves and stems (mg).

\section{Classification of varieties}

The RDW data for 31 rice varieties under 7 nitrogen treatment conditions $\left(1,2,5,10,20,40\right.$, and $\left.80 \mathrm{mg} \mathrm{N} \mathrm{L}^{-1}\right)$ were used in a cluster analysis to classify the differences in response to nitrogen across rice varieties. The cluster analysis was carried out using Ward's hierarchical clustering method with the computer program JMP 6.0 (SAS Institute, Inc., Cary, NC, USA).

\section{Results}

\section{Variations in dry matter production}

Wide variations in dry matter production were observed among landrace and improved varieties in both groups; however, differences in PNUE were not apparent between landrace and improved varieties (data not shown) in each nitrogen treatment.

We also observed a wide variation (24 to $60 \mathrm{mg}$ ) in dry matter production across varieties among nitrogen-free controls (detailed data not shown), which suggested differences in growth at the young vegetative stage related to varietal differences in seed and embryo size or growth rate after germination. To evaluate nitrogen efficiency, it was necessary to control for these effects and differences in initial growth among varieties.

\section{Variations in $R D W$ among varieties}

The 31 rice varieties varied widely in RDW (\%) across all nitrogen levels. RDW and its variation among rice varieties increased with increasing nitrogen concentration in the culture solution. An Indica-type landrace variety, Kasalath, consistently had the highest RDW, and the improved varieties bred at the IRRI or in Japan had the lowest RDWs in all treatment conditions. 
The varieties showed 2 growth patterns in response to high nitrogen concentrations. Three varieties, Kasalath, Basmati 217, and Dular, had increasing RDW with increasing nitrogen concentration, with the highest RDW values observed after $80 \mathrm{mg} \mathrm{N} \mathrm{L}^{-1}$ treatment. The other 28 varieties had a different response; their RDWs did not significantly increase after the nitrogen concentration reached 10 or 20 $\mathrm{mgN} \mathrm{L}^{-1}$.

\section{Classification of rice varieties}

Cluster analysis was carried out using the RDW data, and the 31 rice varieties were grouped into five clusters, I-V (Fig. 1 and Table 1). Clusters I and II consisted of one Indica-type variety, Kasalath, and 2 Japonica-type varieties, Basmati 217 and Dular, respectively, all landrace varieties. Cluster III included 9 Japonica-type varieties, Azucena, Davao, Kibi, Moroberekan, Oiran, Trembese, Kotobukimochi, Owarihatamochi and Dontokoi, all but
Dontokoi are cultivated in upland fields. Cluster IV consisted of 9 varieties, Surjamkuhi, Takanari, Reiho, Kamenoo, Mahsuri, Tadukan, Hokuriku 143, Tetep and Koshihikari; these include both Indica and Japonica-types and both landrace and improved types. Cluster $\mathrm{V}$ consisted of only improved varieties of Indica and Japonica-types, Taichung Native 1, IR 36, IR 8, Akihikari, Aichiasahi, IR 24, Toride 1 Milyang 23, IR 64 and Nipponbare.

These classifications by cluster analysis corresponded to varieties' response to varying nitrogen concentrations (Table 2). The varieties in clusters I and II always had an increased RDW with an increase in nitrogen concentration. The RDWs of Kasalath (cluster I) varied from 325 to $772 \%$ and were much higher than those of cluster II (230 to 542\%). The RDWs of cluster groups III, IV, and V increased up to a nitrogen concentration of $10 \mathrm{mg} \mathrm{N} \mathrm{L}^{-1}$, but did not change significantly at higher nitrogen concentrations. The saturation of RDWs in these 3 clusters was different from the

Table 2. Variations in RDW for each nitrogen treatment by cluster group

\begin{tabular}{|c|c|c|c|c|c|c|c|}
\hline \multirow{3}{*}{$\begin{array}{l}\text { Cluster group } \\
\text { (No. of varieties) }\end{array}$} & \multicolumn{7}{|c|}{$\mathrm{RDW}^{a}$} \\
\hline & \multicolumn{7}{|c|}{ Nitrogen concentration $\left(\mathrm{mg} \mathrm{N} \mathrm{L}^{-1}\right)^{b}$} \\
\hline & 1 & 2 & 5 & 10 & 20 & 40 & 80 \\
\hline $\mathrm{I}(1)$ & $325 \mathrm{a}$ & $364 \mathrm{a}$ & $487 \mathrm{a}$ & $594 \mathrm{a}$ & $630 \mathrm{a}$ & $701 \mathrm{a}$ & $772 \mathrm{a}$ \\
\hline $\mathrm{II}(2)$ & $230 \mathrm{~b}$ & $259 \mathrm{a}$ & $328 \mathrm{~b}$ & $410 \mathrm{~b}$ & $416 \mathrm{~b}$ & $421 \mathrm{~b}$ & $542 \mathrm{~b}$ \\
\hline $\operatorname{III}(9)$ & $205 \mathrm{~b}$ & $228 \mathrm{a}$ & $319 \mathrm{~b}$ & $372 \mathrm{~b}$ & $385 \mathrm{~b}$ & $377 \mathrm{~b}$ & $372 \mathrm{c}$ \\
\hline $\operatorname{IV}(9)$ & $177 \mathrm{~b}$ & $201 \mathrm{a}$ & $256 \mathrm{c}$ & $317 \mathrm{c}$ & $337 \mathrm{c}$ & $353 \mathrm{~b}$ & $337 \mathrm{c}$ \\
\hline $\mathrm{V}(10)$ & $156 \mathrm{c}$ & $202 \mathrm{a}$ & $226 \mathrm{c}$ & $262 \mathrm{~d}$ & $273 \mathrm{~d}$ & $283 \mathrm{c}$ & $277 \mathrm{~d}$ \\
\hline Mean $\pm \mathrm{SD}^{c}$ & $187 \pm 40$ & $218 \pm 48$ & $276 \pm 61$ & $330 \pm 75$ & $345 \pm 78$ & $353 \pm 84$ & $355 \pm 107$ \\
\hline Range & $121-325$ & $150-364$ & $195-487$ & $228-594$ & $234-630$ & $222-701$ & $235-772$ \\
\hline
\end{tabular}

${ }^{a}$ RDW $(\%)=($ Dry matter weight of leaves and stems $(\mathrm{DW}, \mathrm{mg})$ of $\mathrm{N}$ treatment/DW of non-N control) $\times 100$.

${ }^{b}$ Within the same column, means not followed by the same letter are significantly different at $P<0.05$ based on Tukey's test.

${ }^{c}$ Mean \pm SD and range indicate the mean and standard deviation, and variation from minimum to maximum among the 31 varieties.

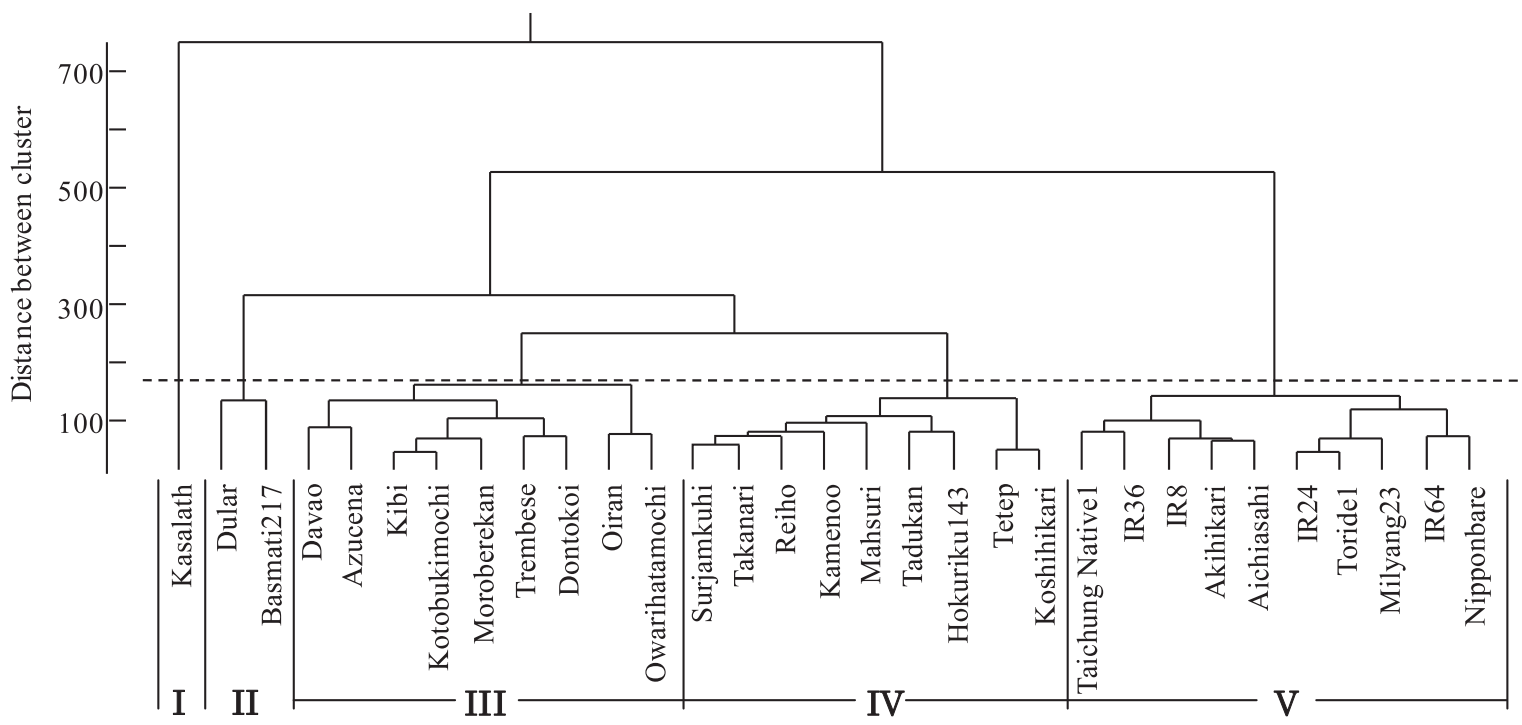

Fig. 1. Classification of cultivars by cluster analysis based on response to nitrogen. The relative dry weight (RDW, \%) of 7 treatment groups (1, $2,5,10,20,40$, and $80 \mathrm{mg} \mathrm{N} \mathrm{L}^{-1}$ ) compared to a nitrogen-free control after 14 days of growth was used for the cluster analysis. The dendrogram was calculated and drawn using the Ward hierarchical clustering method, and the 31 varieties were classified into 5 groups. 
response observed in clusters I and II. The RDWs of cluster III were higher (205 to $385 \%$ ), cluster $\mathrm{V}$ had the lowest RDWs (156 to $283 \%$ ), and cluster IV had intermediate RDWs (177 to $337 \%$ ).

Significant differences in RDW across cluster groups I to $\mathrm{V}$ were recognized using Tukey's test at 6 nitrogen concentrations, 1 and $5-80 \mathrm{mg} \mathrm{NL}^{-1}$. Based on these significant differences, the 5 clusters were classified into 3 groups at the lowest concentration $\left(1 \mathrm{mg} \mathrm{N} \mathrm{L}^{-1}\right)$ : cluster I; clusters II, III and IV; and cluster $\mathrm{V}$. In the middle concentration range from 10 to $20 \mathrm{mg} \mathrm{N} \mathrm{L}^{-1}$, they were classified into 4 groups: cluster I, clusters II and III, cluster IV, and cluster V. At the highest concentration $\left(80 \mathrm{mg} \mathrm{NL}^{-1}\right)$ they were classified into a different set of 4 groups: cluster I, cluster II, clusters III and IV, and cluster V. These results suggest that the 5 clusters differed in their dry matter production responses to varying nitrogen concentrations in solution.

\section{Variations in PNUE}

The values of PNUE for each varietal cluster decreased with increasing nitrogen concentration; however, the decrease was not significant beyond $2-10 \mathrm{mg} \mathrm{N} \mathrm{L}^{-1}$ (Table 3 ). Kasalath in cluster I had the highest PNUE values (33.9 to $22.2)$ over the concentration range $1-80 \mathrm{mg} \mathrm{N} \mathrm{L}^{-1}$, and cluster $\mathrm{V}$ had the lowest values (22.1 to 15.5$)$ in all treatment groups except $2 \mathrm{mgNL}^{-1}$. This finding demonstrates that the landrace variety Kasalath in cluster I was able to use nitrogen most effectively for dry matter production, and the improved varieties in cluster $\mathrm{V}$ the least. The other 3 clusters were intermediate between clusters I and V.

\section{Characterization of varieties based on the relationship} between RDW and PNUE

Figure 2 shows the distribution of the 31 varieties based on the relationship between their PNUE and RDW values at $20 \mathrm{mg} \mathrm{N} \mathrm{L}^{-1}$ as one of the typical variations and distribution for nitrogen responses among the different nitrogen concentrations. A wide variation among these varieties and a posi- tive correlation between PNUE and RDW were observed. PNUE and RDW ranged from 13.2 to 22.0, and from 234 to $630 \%$, respectively, at $20 \mathrm{mg} \mathrm{N} \mathrm{L}^{-1}$.

Cluster I had the highest PNUE and RDW values, while cluster $\mathrm{V}$ had the lowest. The values of the other 3 clusters were intermediate between these 2 clusters for all nitrogen concentrations. The variation in RDW in cluster $\mathrm{V}$ was not large, but PNUE varied substantially from 13.2 to 19.0 with a tendency for Indica-type varieties to have a lower PNUE than Japonica-type varieties.

\section{Discussion}

A wide variation in nitrogen response at the young vegetative stage was observed in 31 rice varieties including Indica and Japonica-types adapted to irrigated lowland or to upland environments and landrace and improved variations.

These varieties were classified into 5 groups, I to V, through cluster analysis of RDW under different nitrogen concentration conditions. The Indian landrace variety Kasalath (comprising cluster I) was the most sensitive to nitrogen as indicated by both RDW and PNUE, and the improved varieties in cluster $\mathrm{V}$ were the most insensitive to nitrogen. Clusters II, III, and IV were intermediate between clusters I and V. Cluster III included mainly upland varieties and differed from cluster IV in PNUE values. These results suggest that variations may originate from the degree of improvement, from landraces to recent varieties developed by cross-breeding, and adaptations to irrigated lowland or upland soil conditions. A tendency for the PNUE of Japonicatype varieties to be higher than that of Indica-type was observed in cluster V. Ichii and Tsumura (1989) reported also that 25 Indica-type varieties had a higher rate of ammonium nitrogen absorption than 51 Japonica-type varieties. It was suggested that the differentiation of Japonica and Indicatypes' varieties might also be related to variations in nitrogen metabolism.

The Green Revolution in rice was initiated at IRRI in the

Table 3. Variations in PNUE for each nitrogen treatment by cluster group

\begin{tabular}{|c|c|c|c|c|c|c|c|}
\hline \multirow{3}{*}{$\begin{array}{l}\text { Cluster group } \\
\text { (No. of varieties) }\end{array}$} & \multicolumn{7}{|c|}{$\mathrm{PNUE}^{a}$} \\
\hline & \multicolumn{7}{|c|}{ Nitrogen concentration $\left(\mathrm{mg} \mathrm{N} \mathrm{L}^{-1}\right)^{b}$} \\
\hline & 1 & 2 & 5 & 10 & 20 & 40 & 80 \\
\hline $\mathrm{I}(1)$ & $33.9 \mathrm{a}$ & $28.8 \mathrm{a}$ & $24.6 \mathrm{a}$ & $22.4 \mathrm{a}$ & $21.8 \mathrm{a}$ & $22.9 \mathrm{a}$ & $22.2 \mathrm{a}$ \\
\hline $\mathrm{II}(2)$ & $28.4 \mathrm{a}$ & $24.1 \mathrm{a}$ & $20.7 \mathrm{a}$ & $20.3 \mathrm{a}$ & $19.0 \mathrm{~b}$ & $19.8 \mathrm{ab}$ & $19.1 \mathrm{ab}$ \\
\hline III(9) & $29.2 \mathrm{a}$ & $25.1 \mathrm{a}$ & $21.8 \mathrm{a}$ & $20.9 \mathrm{a}$ & $19.8 \mathrm{a}$ & $19.1 \mathrm{~b}$ & $18.3 \mathrm{~b}$ \\
\hline $\operatorname{IV}(9)$ & $26.6 \mathrm{a}$ & $22.2 \mathrm{a}$ & $18.7 \mathrm{a}$ & $18.4 \mathrm{a}$ & $18.6 \mathrm{~b}$ & $18.6 \mathrm{~b}$ & $17.4 \mathrm{~b}$ \\
\hline $\mathrm{V}(10)$ & $22.1 \mathrm{~b}$ & $22.7 \mathrm{a}$ & $16.5 \mathrm{a}$ & $16.3 \mathrm{a}$ & $16.4 \mathrm{~b}$ & $16.3 \mathrm{c}$ & $15.5 \mathrm{c}$ \\
\hline Mean $\pm \mathrm{SD}^{c}$ & $26.3 \pm 5.5$ & $23.6 \pm 3.8$ & $19.6 \pm 2.6$ & $19.0 \pm 2.3$ & $18.4 \pm 1.9$ & $18.2 \pm 1.8$ & $17.3 \pm 1.8$ \\
\hline Range $^{c}$ & $13.2-33.9$ & $16.5-30.8$ & $14.5-24.6$ & $14.4-22.4$ & $13.2-22.0$ & $14.3-22.9$ & $13.7-22.2$ \\
\hline
\end{tabular}

a PNUE: Physiological nitrogen use efficiency of dry matter production per $1 \mathrm{mg}$ of absorbed nitrogen. PNUE= Dry matter weight of the leaves and stems (DW, mg) of $\mathrm{N}$ treatment- $\mathrm{DW}$ of non- $\mathrm{N}$ control/Nitrogen content of the leaves and stems $(\mathrm{NC}, \mathrm{mg})$ of $\mathrm{N}$ treatment $-\mathrm{NC}$ of non- $\mathrm{N}$ control.

${ }^{b}$ Within the same column, means not followed by the same letter are significantly different at $P<0.05$ based on Tukey's test.

${ }^{c}$ Mean $\pm \mathrm{SD}$ and range indicate the mean and standard deviation, and variation from minimum to maximum among the 31 varieties. 


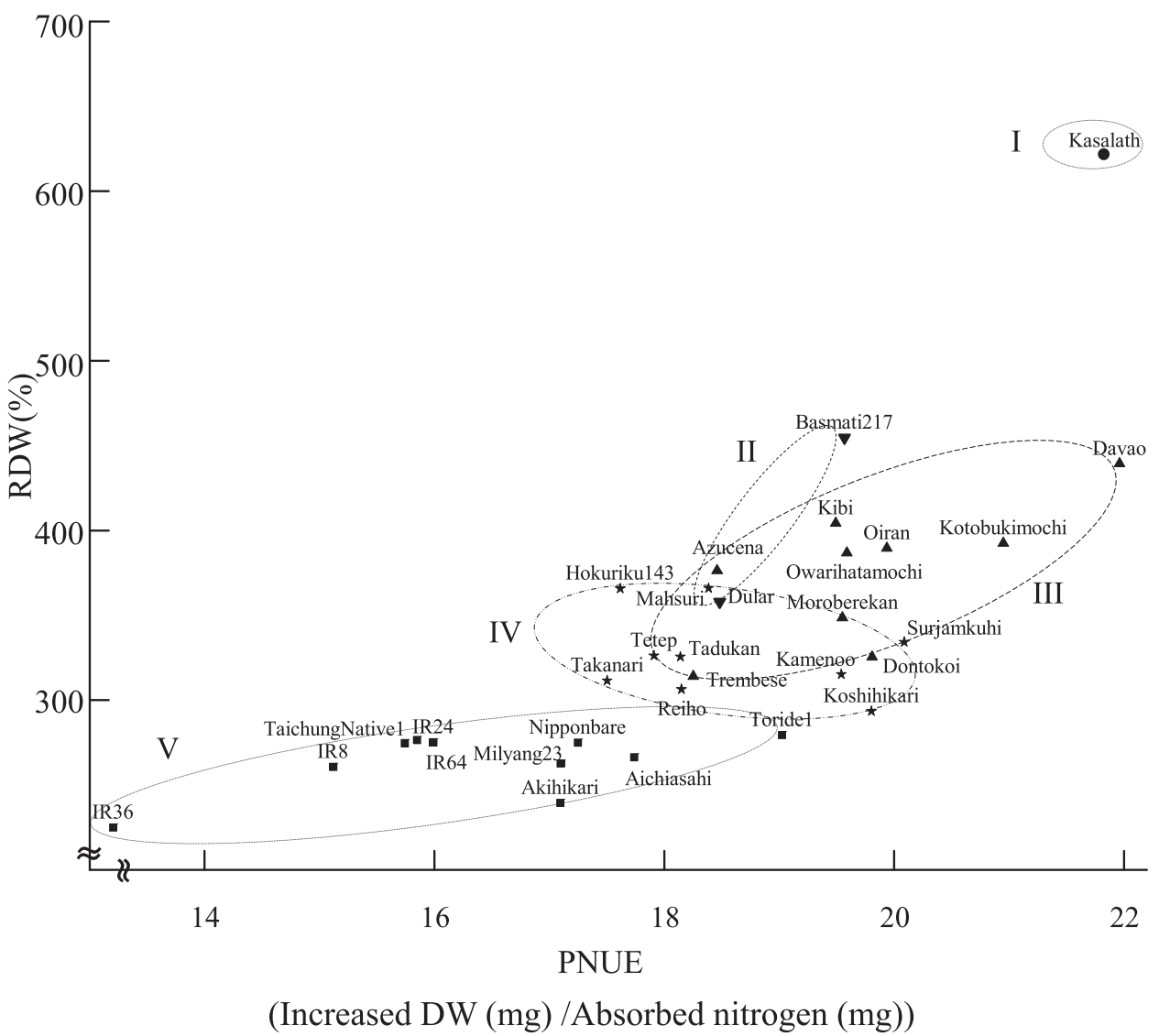

Fig. 2. Relationship between PNUE and RDW for all varieties at $20 \mathrm{mg} \mathrm{N}^{-1}$ treatment. PNUE: Physiological nitrogen use efficiency of dry matter production per $1 \mathrm{mg}$ absorbed nitrogen. PNUE = Dry matter weight of the leaves and stems (DW, mg) of N treatment-DW of non-N control/ Nitrogen content of the leaves and stems $(\mathrm{NC}, \mathrm{mg})$ of $\mathrm{N}$ treatment $-\mathrm{NC}$ of non-N control. RDW $(\%)=(\mathrm{DW}$ of $\mathrm{N}$ treatment/DW of non-N control) $\times 100$. I-V denote the groups resulting from the cluster analysis. $r$ : correlation coefficient. Two asterisks $(* *)$ on the shoulders of the correlation coefficient shows indicate the $1 \%$ level of significant difference in each nitrogen treatment.

1960s through the development of high-yield varieties using a semi-dwarf gene, $s d-1$, derived from an Asian cultivated rice (Oryza sativa L.), and these varieties were bred in an environment with high levels of chemical fertilizers and pesticides (Fischer 1998, Khush 1999, Spielmeyer et al. 2002). Both Indica and Japonica-types' improved varieties were commonly bred at IRRI (tropical) and in Japan (temperate), and they were characterized by low dry matter production under high nitrogen conditions. The Indica-type varieties IR 8, IR 24, IR 36, IR 64, Taichung Native 1 and Milyang 23 in cluster $\mathrm{V}$ were bred by crossing and introducing $s d-1$ (Ashikari et al. 2002, Nagata 2006). Japanese breeding and research to obtain high-yielding varieties were applied small numbers of varieties in the early 1930s (Ohata 1989), and adaptability to heavy manuring was reported by Takahashi et al. (1959), Takeda and Kumura (1959), Iwata and Baba (1962), and Osada and Murata (1962). In these breeding studies, rice varieties that did not show luxuriant or spindly growth under high nitrogen conditions were developed and characterized (Baba 1956). Indica-type varieties and Japonica-type varieties such as Nipponbare and Akihikari in cluster V were bred for high adaptability to heavy manuring (Koumura 1972a, 1972b, Kushibuchi et al. 1977).
In contrast, the 3 varieties in clusters I and II are landraces with high sensitivity to nitrogen, but there were differences in RDW and PNUE between clusters I and II. These results suggest that variations in response to nitrogen also exist among landrace varieties. It would be beneficial in further NUE studies to investigate the variation in nitrogen response among more varieties of landraces.

The majority of cluster III was comprised of upland varieties. Ammonium nitrogen is the main nitrogen source for rice in irrigated lowlands, while nitrate is the main nitrogen source in upland conditions (Sumida 1992). Ichii and Tsumura (1989) reported that the rate of nitrogen absorption was significantly higher in lowland varieties than in upland, but there were no significant differences in dry weight between them. The upland varieties may exploit a different system for nitrogen absorption/utilization than lowland varieties. The responses of these rice varieties to different nitrogen sources, ammonium and nitrate, should also be confirmed.

Detailed genetic and physiological backgrounds of the varieties in the 5 clusters have not yet been identified. The recent development of molecular marker techniques enables localization of putative gene loci for agronomic traits of 
interest, or quantitative trait loci (QTL), and estimation of the magnitudes of their effects (Yano 2001, Varshney et al. 2005). QTL analysis is therefore a promising tool for exploring the genetic basis of nitrogen response across rice varieties. Using hybrid populations developed from the varieties used in the present study, QTL analysis will be carried out to identify significant genetic factors affecting nitrogen response.

In this study, nitrogen response in rice at an early growth stage was investigated. In the future it may be valuable to study nitrogen response at the reproductive stage.

Overall, the present study found that there are wide variations in PNUE among varieties with similar RDW under low to high nitrogen conditions. Variations in PNUE were greater under lower nitrogen conditions; in contrast, variations in RDW were greater under higher nitrogen conditions. These data, along with those of other studies, suggest differences in NUE between Indica- and Japonica-types, between upland and lowland varieties, and between landraces and improved types. The results provide information needed to breed suitable varieties for cultivation under low soil fertility conditions or for sustainable agriculture using different fertilizers.

\section{Acknowledgments}

This research was carried out as part of a JIRCAS research project, "Development of abiotic stress-tolerant crops". We would like to thank Dr. Takashi Kumashiro, Director of the Biological Resource Division, and Dr. Osamu Ito, Director of the Crop Production and Environment Division, for their kind support of this study.

\section{Literature Cited}

Amin, S.M.N., N. Uchida, T.Hatanaka, T.Azuma, T. Yasuda and H.Tsugawa (2002) Varietal differences of rice (Oryza sativa L.) growth to low nitrogen supply. Environ. Control Biol. 40: 195200.

Ashikari,M., A.Sasaki, M.Ueguchi-Tanaka, H.Itoh, A.Nishimura, S.Datta, K.Ishiyama, T.Saito, M.Kobayashi, G.S.Khush et al. (2002) Loss-of-function of a rice gibberellins biosynthetic gene, GA20 oxidase (GA20ox-2), led to the rice 'Green Revolution'. Breed. Sci. 52: 143-150.

Athwal,D.S. (1971) Semidwarf rice and wheat in global food needs. Q. Rev. Biol. 46: 1-34.

Baba,I. (1956) Chapter 7. Adaptability for heavy manuring. In: Togari, Y., Matsuo,T. (eds.) Rice Crop Course 1, Asakura-shoten, Tokyo, pp. 65-73.

Bohlool,B.B., J.K.Ladha, D.P.Garrity and T.George (1992) Biological nitrogen fixation for sustainable agriculture: a perspective. Plant Soil 141: 1-11.

Boys,A.F.F. (2005) Energy inputs to agriculture. Energy and Resources 26: 27-32 (in Japanese, J-EAST provides English text).

Chang, T.T. (1961) Recent advances in rice breeding in Taiwan. In: Chinese-American Joint Commission on Rural reconstruction (ed.) Plant Industry Series 22, Crop and seed improvement in Taiwan, Republic of China, Taipei, pp.33-58.
Ehara,H., M.Tsuchiya and T.Ogo (1990) Fundamental growth response to fertilizer in rice plants I. Varietal difference in the growth rate at the seedling stage. Jpn. J. Crop Sci. 59: 426-434.

Fageria,N.K., V.C.Baligar and Y.C.Li (2008) The role of nutrient efficient plants in improving crop yields in the twenty first century. J. Plant Nutr. 31: 1121-1157.

Fischer,K.S. (1998) Toward increasing nutrient-use efficiency in rice cropping systems: the next generation of technology. Field Crops Res. 56: 1-6.

Fukuta, Y., H.Yoshida, K.Fukui and A.Kobayashi (1994) Analysis of shattering degree and abscission layer development in shatteringresistant mutant lines induced from an indica rice (Oryza sativa L.) variety, Nan-jin11. Breed. Sci. 44: 195-200.

Good,A.G., A.K.Shrawat and D.G.Muench (2004) Can less yield more? Is reducing nutrient input into the environment compatible with maintaining crop production? Trends Plant Sci. 9: 597-605.

Hasegawa,H. (2003) High-yielding rice cultivars perform best even at reduced nitrogen fertilizer rate. Crop Sci. 43: 921-926.

Ichii,M. and H.Tsumura (1989) Comparison of the nutrient uptake in ecospecies and ecotypes of rice seedlings. Jpn. J. Crop Sci. 58: 712.

Imbe, T., Y.Akama, A.Nakane, T.Hata, K.Ise, I.Ando, H.Uchiyamada, N.Nakagawa, H.Furutachi, N.Horisue et al. (2004) Development of a multipurpose high-yielding rice variety "Takanari”. Bull. Natl. Inst. Crop Sci. 5: 35-51.

Iwata,I. and I.Baba (1962) Studies on the varietal adaptability for heavy manuring in rice. 2 . Effect of silica upon the adaptability of the rice plant for heavy manuring in relation to photosynthesis. Jpn. J. Crop Sci. 30: 237-240.

Ju, J., Y.Yamamoto, Y.Wang, Y.Shan, G.Dong, T.Yoshida and A.Miyazaki (2006) Genotypic difference in grain yield, and nitrogen absorption and utilization in recombinant in bred lines of rice under hydroponic culture. Soil Sci. Plant Nutr. 52: 321-330.

Khush,G.S. (1999) Green revolution: preparing for the 21 st century. Genome 42: 646-655.

Koumura,T. (1972a) Breeding of new rice variety "Nipponbare" (1). Agricultural Technique 27: 112-116.

Koumura, T. (1972b) Breeding of new rice variety "Nipponbare" (2). Agricultural Technique 27: 159-161.

Kushibuchi, K., H.Sato, T. Kanazawa, Z. Oyamada, N. Nakagawa, M.Namioka, T.Takemura, T.Nakahori, M.Takadate and R.Sato (1977) A new rice variety "Akihikari". Bull. Aomori Agric. Exp. Stn. 22: 1-22.

Ladha,J.K., G.J.D.Kirk, J.Bennett, S.Peng, C.K.Reddy, P.M.Reddy and U.Singh (1998) Opportunities for increased nitrogen-use efficiency from improved lowland rice germplasm. Field Crops Res. 56: 41-71.

Lafitte,H.R. (1998) Research opportunities to improve nutrient-use efficiency in rice cropping systems. Field Crops Res. 56: 223-236.

Mae,T. and K.Ohira (1981) The remobilization of nitrogen related to leaf growth and senescence in rice plants (Oryza sativa L.). Plant \& Cell Physiol. 22: 1067-1074.

Nagai,K., H.Fujimaki and M.Yokoo (1970) Breeding of rice variety Toride 1 with multi-racial resistance to leaf blast. Jpn. J. Breed. 20: $7-14$.

Nagata,K. (2006) Ecophysiological traits and genetic analysis of yield and ripening in high-yielding semi-dwarf Indica rice varieties. JARQ 40: 307-316.

Ohata, K. (1989) Changes of varieties and disease. In: Disease of rice 'diagnosis, ecology, prevention'. Japanese Society of Rural Education, Tokyo, pp.43-47. 
Osada,A. and Y.Murata (1962) Studies on the relationship between photosynthesis and varietal adaptability for heavy manuring in rice plant I. The relationship in the case of medium-maturing varieties. Jpn. J. Crop Sci. 30: 220-223.

Peng, S., G.S.Khush, P.Virk, Q.Tang and Y.Zou (2008) Progress in ideotype breeding to increase rice yield potential. Field Crops Res. 108: 32-38.

Raun, W.R. and G.V.Johnson (1999) Improving nitrogen use efficiency for cereal production. Agron. J. 91: 357-363.

Samonte, S.O.P.B., L.T.Wilson, J.C.Medley, S.R.M.Pinson, A.M. McClung and J.S.Lales (2006) Nitrogen utilization efficiency: relationships with grain yield, grain protein, and yield-related traits in rice. Agron. J. 98: 168-176.

Singh,U., J.K.Ladha, E.G.Castillo, G.Punzalan, A.Tirol-Padre and M.Duqueza (1998) Genotypic variation in nitrogen use efficiency in medium- and long-duration rice. Field Crops Res. 58: 35-53.

Spielmeyer, W., M.H.Ellis and P.M.Chandler (2002) Semidwarf $(s d-1)$, "green revolution" rice, contains a defective gibberellins 20-oxidase gene. PNAS 99: 9043-9048.

Sumida,H. (1992) Effect of nitrogen nutrition on silica uptake by rice plant. Jpn. J. Soil Sci. Plant Nutr. 63: 633-638.

Takahashi,Y., I.Iwata and I.Baba (1959) Studies on the varietal adaptability for heavy manuring in rice. Jpn. J. Crop Sci. 28: 22-24.

Takeda, T. and A.Kumura (1959) Analysis of grain production in rice plant V. Analytical studies on the varietal tolerability for heavy manuring in paddy rice. Jpn. J. Crop Sci. 28: 179-181.

Varshney,P.K., A.Graner and M.E.Sorrells (2005) Genomics-assisted breeding for crop improvement. Trends Plt. Sci. 10: 621-630.

Yamakawa,H., H.Fujii, J.Kawakami and S.Samoto (1977) Studies on breeding Malinja, Mahsuri and Bahagia, new rice varieties for double cropping in Malaysia. Jpn. J. Trop. Agric. 21: 40-42.

Yano,M. (2001) Genetic and molecular dissection of naturally occurring variation. Cur. Op. Plt. Bio. 4: 130-135. 